\title{
United States experience of insulin degludec alone or in combination for type I and type 2 diabetes
}

This article was published in the following Dove Press journal:

Drug Design, Development and Therapy

13 April 2017

Number of times this article has been viewed

\author{
Marc Rendell ${ }^{1,2}$ \\ 'The Rose Salter Medical Research \\ Foundation, ${ }^{2}$ The Association of \\ Diabetes Investigators, Newport \\ Coast, CA, USA
}

\begin{abstract}
Insulin degludec has been the product of a sophisticated and systematic biochemical engineering program which began with the release of insulin detemir. The goal was to produce a long-lasting basal insulin with low individual variability. Certainly, this goal has been achieved. Degludec has a duration of action approaching twice that of glargine. Another advantage of degludec is in its lack of unpredictable copolymerization of added aspart. In several studies, degludec has shown lower rates of nocturnal hypoglycemia than glargine. Degludec can be administered flexibly with a very flat insulin concentration curve at any time of day. Initial US Food and Drug Administration concerns about a possible increase in cardiac events in degludec-treated patients have been allayed by the results of a study targeting individuals with high cardiac risk. Degludec is now marketed in the US competing with glargine. Despite the long duration of action of degludec, attempted administration three times weekly resulted in less effective lowering of glycated hemoglobin and an increased incidence of hypoglycemia compared to daily glargine. Conversely the coformulation of degludec and liraglutide has proven very successful in reducing glycated hemoglobin levels with less hypoglycemia and less weight gain than with degludec alone and with less gastrointestinal symptoms than with liraglutide alone. A large study comparing glargine insulin and degludec in patients with increased cardiac risk is now ongoing. This study may or may not prove superiority of one or the other insulin, but, with the coming of biosimilar glargine insulin, cost factors may be dominant in determining which basal insulin is to be used. Nonetheless, the coformulation with liraglutide will likely insure the future of degludec insulin in the treatment of type 2 diabetes.
\end{abstract}

Keywords: insulin degludec, insulin glargine, hypoglycemia, liraglutide

\section{Introduction}

Childhood diabetes was a progressive, fatal disease until the 1920s. In 1889, Minkowski and von Mering showed that removal of the pancreas caused diabetes. In 1920, Dr Frederick Banting, a Canadian surgeon, and Charles Best, and John MacLeod pursued experiments to extract insulin from animal pancreas. ${ }^{1}$ Bertram Collip, a biochemist, joined in the effort to purify the extract to remove pancreatic enzymes. Their success began with the administration of their purified product to Leonard Thompson, a 14 year old boy dying of diabetes. His survival quickly led to pharmaceutical efforts to offer insulin derived from beef pancreas to many other children. The product, crystalline zinc insulin (CZI), was a life-saving development for patients throughout the world. CZI was relatively short acting, usually with peak effect on blood sugar elevations within 2 hours after subcutaneous injection, and waning of effect after 7-8 hours.

HC Hagedorn, the Danish diabetologist, realized that a longer-acting insulin would help to stabilize the peaks and valleys resulting from multiple injections of CZI. He complexed insulin with protamine and zinc to form a repository insulin, 
protamine zinc insulin, which slowly released insulin for up to several days. ${ }^{2}$ He continued to develop various forms of repository insulin, and, in 1946, his group introduced Neutral Protein Hagedorn (NPH) insulin. ${ }^{3} \mathrm{NPH}$ insulin was not as long lasting as protamine zinc insulin but had the advantage of not binding coinjected regular insulin, so that the two formulations could be administered in the same syringe. Another long-acting insulin, named Ultralente, was developed by modifying zinc concentration of suspensions of zinc-crystallized insulin with varying rates of release of insulin from the subcutaneous repository., ${ }^{4,5}$ Ultralente insulin was a very long-acting suspension with duration of activity of 36-48 hours. Regular insulin could not be mixed with Ultralente insulin due to interaction, resulting in slowed absorption. ${ }^{6}$ These long-acting preparations were useful, but showed significant variability in release of insulin and in glucose-lowering effects, with unpredictable insulin peaks that promoted hypoglycemia.

A new era began in 1995 with the development of insulin analogs with modified peptide sequences. The first was Lispro insulin, an analog of the human insulin peptide B chain with lysine substituted at position 28 and proline at position 29. Insulin tends to self-associate into dimers. Three dimers combine with two zinc ions to form hexamers in $\beta$ cell vesicles. With release of insulin into the circulation, the hexamers lose their zinc core and dissociate into dimers and monomers, which are active at the insulin receptor. The kinetics of injected insulin can be accelerated when dimers rapidly dissociate into monomers. The Lispro substitutions promoted rapid dissociation of the injected insulin, resulting in more rapid absorption and a shorter duration of action than regular human insulin. ${ }^{7}$

Insulin glargine was an insulin analog developed in 2000 to produce a long-acting, stable release of insulin from the subcutaneous site of injection. The structure of glargine differs from that of human insulin by glycine substitution for an asparagine at position $\mathrm{A} 21$ and by addition of arginine to the carboxyl terminal of the B chain at positions B31 and B32. These amino acid modifications change the isoelectric point of the molecule closer to neutral (from pH 5.4 to 6.8), making glargine soluble in a vial adjusted to this lower $\mathrm{pH}$ but insoluble at the neutral $\mathrm{pH}$ of the subcutaneous injection site. ${ }^{8}$ When injected subcutaneously, glargine forms microprecipitates from which insulin is slowly released. ${ }^{9}$ The onset of action of glargine is about $1.5 \mathrm{hrs}$. The insulin serum concentration/time profile is relatively constant over 18 hours, with a slow decrement in the time period of 20-24 hours, making it almost a 24-hour duration basal insulin. ${ }^{10,11}$
Glargine is used to provide a relatively constant basal insulin level in both type 1 and type 2 diabetes. NPH insulin does not have as long a duration of action as glargine and develops peak concentrations at which hypoglycemia is more likely to occur. The most important advantage of glargine over NPH is reduction in the risk of hypoglycemia, primarily at night. This advantage derives from the very flat pharmacokinetic profile of glargine, demonstrated in multiple studies. Glargine is superior to NPH in improving glycated hemoglobin $\left(\mathrm{HbA}_{1 \mathrm{c}}\right)$ and fasting glucose levels during intensive insulin therapy in patients with type 1 and type 2 diabetes and is associated with less severe nocturnal hypoglycemia and less weight gain. ${ }^{12-16}$

\section{Design of insulin degludec}

Although glargine has remained the dominant form of longacting insulin for well over a decade, efforts to discover new synthetic basal insulins have continued. Insulin detemir was designed by Novo Nordisk (Bagsværd, Denmark) to promote increased self-association of hexamers and dimers. ${ }^{17}$ Detemir differs from human insulin in that the amino acid threonine in $\mathrm{B} 30$ position (ThrB30) has been removed, and a C14 fatty acid chain has been attached to amino acid B29. Over $98 \%$ of detemir is bound reversibly to serum albumin. Dihexamerization and albumin binding of hexameric and dihexameric detemir prolongs residence time at the injection depot. Some further retention of detemir occurs in the circulation where albumin binding causes buffering of insulin concentration. ${ }^{17}$ Detemir has a duration of action which is dose dependent varying from 6 hours for doses of 0.1 units $/ \mathrm{kg}$ up to 23 hours for higher doses in the range of 1.6 units $/ \mathrm{kg} .{ }^{18,19}$ The duration of detemir activity is significantly less than that of glargine, but the insulin levels produced by administration of detemir show less individual variability. ${ }^{20,21}$

Novo Nordisk pursued further modifications of the longacting insulin analogs. Insulin degludec, developed by Novo Nordisk in a continuation of the development program which produced detemir, has been a recent addition to the available options. Insulin degludec has a similar structure to detemir in the deletion of threonine in the ThrB30 on the insulin B peptide chain. The structure differs from detemir in the addition of a 16-carbon fatty diacid side chain attached to lysine in position B29 (LysB29) via a glutamic acid linker. ${ }^{22,23}$ In the pharmaceutical formulation which contains zinc, phenol, and $\mathrm{m}$-cresol, degludec forms finite dihexamers that are composed of hexamers in the $\mathrm{T}(3) \mathrm{R}(3)$ state that interact to form an $\mathrm{R}(3) \mathrm{T}(3)-\mathrm{T}(3) \mathrm{R}(3)$ structure. After injection, with dispersal of phenol, degludec self-associates to form arrays 
of hundreds of hexamers that precipitate in the subcutaneous tissue environment. Slow diffusion of zinc ions from this depot results in a continuous and highly predictable slow dissociation of insulin monomers. ${ }^{22,23}$ The degludec monomers behave identically to human insulin with respect to insulin receptor binding kinetics and further activation of tyrosine kinase and other insulin receptor activation pathways. The metabolic effects of degludec assessed in multiple species are identical to those of human insulin.

After injection of insulin degludec, insulin levels rise immediately with very slight upslope reaching a maximal level after 10-12 hours, from which there is a very slow decline with a $t_{\max }$ of 10-12 hours and a $t_{1 / 2}$ of 17-21 hours. ${ }^{24,25}$ This is roughly twice the duration of action of glargine, until now the longest acting insulin. ${ }^{26}$ Furthermore the pharmacodynamic effect of degludec shows less variability than that of glargine. ${ }^{27}$ As a result, insulin levels and glucose metabolism are both more predictable after an injection of degludec than after glargine administration. Although the increased duration of action and decreased variability of glucose-lowering effect of degludec appear very advantageous as compared to glargine, it must be remembered that insulin administration is a recurrent event. It is the steady state which is of practical clinical importance. There is evidence that degludec shows lower variability than glargine in the steady state. ${ }^{28}$

Another important property of degludec not shared by glargine is limited miscibility with rapid acting insulin. Coadministration of glargine with rapid-acting insulin analogs such as insulin Lispro leads to modification of the pharmacokinetics and pharmacodynamics of the short-acting insulin. As a result, glargine is not approved to be codelivered with rapid-acting insulin in the same syringe. Although there is inevitably an effect of degludec on coadministered aspart insulin, in particular lower aspart action in the first few hours after injection, Novo Nordisk has been able to successfully prepare a $70 \%$ degludec- $-30 \%$ aspart coformulation. ${ }^{29,30}$ This combination has been characterized in terms of kinetics and glucose-lowering activity. ${ }^{31,32}$

This 70-30 degludec-aspart preparation is similar to the coformulation of NPH and either aspart or Lispro insulins and allows for less total injections. So, whereas glargine and rapid-acting insulins are administered in different syringes at alternate sites, the fixed ratio 70/30 degludec-aspart combination can be given as a single shot. However, aspart and degludec cannot be given in a combined injection in a flexible ratio while still maintaining predictable rapid-acting properties of aspart.

\section{Clinical studies}

The clinical development program for degludec consisted of 25 clinical pharmacology trials and eleven therapeutic trials. In addition, there were five Phase 3 trials evaluating degludec-aspart. In the degludec and degludec-aspart Phase 3 trials, 5,635 patients were exposed to degludec or degludec-aspart with 3,306 exposed to comparators, mainly glargine. Of the 8,941 patients in the Phase 3 trials, 6,830 (76.4\%) had type 2 diabetes and 2,111 (23.6\%) had type 1 diabetes. Of the type 2 diabetes patients, 3,018 (44.2\%) were insulin-treated prior to the trials, while 3,812 (55.8\%) had not received insulin. The design of the studies was tailored to illustrate the advantages of degludec. In particular, degludec was administered in a Treat to Target approach with an aggressive titration goal of prebreakfast self-measured plasma glucose titration target between 70 and $90 \mathrm{mg} / \mathrm{dL}$ (3.9-4.9 mmol/L). Basal insulin doses were adjusted weekly for the first 6 months based on a titration algorithm to ensure treatment uniformity between trial sites and across trials. The same titration algorithm was used for degludec and for comparator insulin products. This is significant because there was no particular time of daily dosage specified for glargine. So, whether given in the morning to maximize effect at time of meals, or given in the evening, glargine was subject to a forced titration with unique goal of lowering the fasting glucose level. Due to the impossibility of masking the type of insulin pen used, all comparator trials were open label. The main objective of the Phase 3 trials was to confirm the long-term glycemic improvements with degludec or degludec-aspart as measured by $\mathrm{HbA}_{1 \mathrm{c}}$ either in combination with oral hypoglycemic agents in type 2 diabetes or in combination with rapid-acting bolus insulin in both type 1 and type 2 diabetes.

The key objective measurement parameters were, 1) change in $\mathrm{HbA}_{1 \mathrm{c}}$ from baseline, the primary endpoint in all trials, 2) fasting plasma glucose (FPG), and 3) episodes of confirmed hypoglycemia and nocturnal confirmed hypoglycemia. Hypoglycemia was defined as a measured glucose of $<56 \mathrm{mg} / \mathrm{dL}$ ( $3.1 \mathrm{mmol} / \mathrm{L})$, regardless of symptoms. Novo Nordisk has historically used this cut-off level to define hypoglycemia, rather than the American Diabetes Association criteria ( $<70 \mathrm{mg} / \mathrm{dL}(3.9 \mathrm{mmol} / \mathrm{L})$, because $<56 \mathrm{mg} / \mathrm{dL}$ is typically where counterregulatory mechanisms begin and patients report clinical symptoms of hypoglycemia. Furthermore, the cutoff of $56 \mathrm{mg} / \mathrm{dL}$ was sufficiently below the target prebreakfast self-measured plasma glucose $70-90 \mathrm{mg} / \mathrm{dL}$ (3.9-5.0 $\mathrm{mmol} / \mathrm{L})$ to avoid a high incidence of clinically irrelevant hypoglycemic episodes with self-measured 
glucose values just below the target. Typically, the glucose measurements were specified at given times between dosing intervals. Severe hypoglycemia was defined as episodes requiring assistance from another person.

Nocturnal hypoglycemia was prospectively defined as episodes occurring between midnight and 6 AM to allow consistent evaluation across trials. Although episodes of hypoglycemia may go unnoticed and therefore be unreported, especially at night when patients are asleep, this is less likely for hypoglycemic episodes with a glucose less than $56 \mathrm{mg} / \mathrm{dL}$ $(3.1 \mathrm{mmol} / \mathrm{L})$, as such episodes are more often associated with symptoms. The interval between midnight and $6 \mathrm{AM}$ is not a period where one would anticipate receiving injections of rapid-acting insulin and therefore should reflect the effect of the basal insulin.

A prespecified meta-analysis of events categorized as major adverse cardiovascular events (MACE) including cardiovascular death, stroke, and acute coronary syndrome (including myocardial infarction and unstable angina pectoris) was conducted. The primary endpoint in the prespecified meta-analysis was the time until the first event.

\section{Key studies}

There were several pivotal studies leading to approval of degludec (Table 1). In a study of type 2 diabetes patients originally treated with oral hypoglycemic agents, 1,030 patients (mean age: 59 years; baseline $\mathrm{HbA}_{1 \mathrm{c}}: 8.2 \%$ ) were randomized
3:1 to receive once-daily degludec or glargine, both with metformin. ${ }^{31}$ The reduction in $\mathrm{HbA}_{1 \mathrm{c}}$ with degludec was similar (noninferior) to that with glargine (1.06\% vs $1.19 \%)$, with an estimated treatment difference of degludec to glargine of $0.09 \%$ (95\% confidence interval [CI]: -0.04 to 0.22$)$. Overall rates of confirmed hypoglycemia were similar, with degludec and glargine at 1.52 vs 1.85 episodes/patient-year of exposure (PYE). Nocturnal confirmed hypoglycemia in the overall population occurred at a lower rate with degludec vs glargine ( 0.25 vs 0.39 episodes/PYE; $P=0.038$ ). A similar percentage of patients in both groups achieved $\mathrm{HbA}_{1 \mathrm{c}}$ levels $<7 \%$ without hypoglycemia. End-of-trial mean daily insulin doses were 0.59 units $/ \mathrm{kg}$ for degludec and $0.60 \mathrm{units} / \mathrm{kg}$ for glargine. ${ }^{32}$

In a similarly designed trial of degludec used together with rapid-acting insulin to treat type 2 diabetes, 755 subjects received degludec and 248 received glargine. ${ }^{33}$ After 1 year, $\mathrm{HbA}_{1 \mathrm{c}}$ had decreased by $1.1 \%$ in the degludec group and $1.2 \%$ in the glargine group ( $P$ : nonsignificant). Rates of overall confirmed hypoglycemia were lower with degludec than glargine (11.1 vs 13.6 episodes per PYE; estimated rate ratio $0.82,95 \%$ CI: $0.69-0.99 ; P=0.0359)$, as were rates of nocturnal confirmed hypoglycemia (1.4 vs 1.8 episodes per PYE; 0.75, CI: [0.58-0.99]; $P=0.0399)$.

Degludec was also compared to glargine, both administered once daily with mealtime aspart in type 1 diabetes patients. ${ }^{34}$ Of 629 participants, 472 were randomly assigned to degludec and 157 to glargine. At 1 year, $\mathrm{HbA}_{1 \mathrm{c}}$ had fallen

Table I Key studies in development of insulin degludec

\begin{tabular}{|c|c|c|c|c|c|}
\hline Study & Study population & $\begin{array}{l}\text { Comparison } \\
\text { agents }\end{array}$ & $\begin{array}{l}\text { Reduction } \\
\text { in } \mathrm{HbA}_{\mathrm{lc}}\end{array}$ & $\begin{array}{l}\text { Hypoglycemic } \\
\text { events (PYE) }\end{array}$ & $\begin{array}{l}\text { Nocturnal } \\
\text { hypoglycemia }\end{array}$ \\
\hline \multirow[t]{2}{*}{ NNI250-357931 } & Type 2 diabetes on metformin & Degludec & $\mathrm{I} .06 \%(\mathrm{D})$ & $\mathrm{I} .52 \%(\mathrm{D})$ & $0.25 \%(\mathrm{D})$ \\
\hline & & Glargine & $1.19 \%(G)$ & $1.85 \%(G)$ & $0.39 \%(\mathrm{G})^{*}$ \\
\hline \multirow[t]{2}{*}{ NNI $250-3582^{32}$} & Type 2 on basal plus premeal & Degludec & $\mathrm{I} .1 \%(\mathrm{D})$ & $11.1 \%$ (D) & $\mathrm{I} .4 \%(\mathrm{D})$ \\
\hline & rapid-acting insulin & Glargine & $\mathrm{I} .2 \%(\mathrm{G})$ & $13.6 \%(\mathrm{G}) *$ & $\mathrm{I} .8 \%(\mathrm{G})$ \\
\hline \multirow[t]{2}{*}{ BEGIN Basal Bolus Type $I^{33}$} & Type I diabetes & Degludec & $0.4 \%(D)$ & $42.5 \%(D)$ & $4.4 \%(D)$ \\
\hline & & Glargine & $0.39 \%(\mathrm{G})$ & $40.2 \%(\mathrm{G})$ & $5.9 \%(\mathrm{G})^{*}$ \\
\hline \multirow[t]{3}{*}{ Flex Type ${ }^{34}$} & Type I diabetes & Degludec fixed time & $-0.41 \%(\mathrm{D})$ & $88.3 \%(D)$ & $9.6 \%(D)$ \\
\hline & & Degludec Flex time & $-0.40 \%$ (DF) & $82.4 \%$ (DF) & $6.2 \%$ (DF) \\
\hline & & Glargine & $-0.58 \%(G)$ & $79.7 \%(G)$ & $10.0 \%(G)$ \\
\hline \multirow[t]{3}{*}{ Flex Type $2^{35}$} & Type 2 diabetes & Degludec fixed time & $-1.07 \%(D)$ & $3.6 \%(D)$ & $0.6 \%(D)$ \\
\hline & & Degludec Flex time & $-1.28 \%(\mathrm{DF})$ & $3.6 \%$ (DF) & $0.6 \%$ (DF) \\
\hline & & Glargine & $-1.26 \%(\mathrm{G})$ & $3.5 \%(G)$ & $0.8 \%(G)$ \\
\hline \multirow[t]{3}{*}{ NN9068-3697 (DUAL-I) $)^{53}$} & Type 2 diabetes on metformin or & Degludec-Liraglutide & $1.9 \%(D-L)$ & $1.8 \%(\mathrm{D}-\mathrm{L})$ & not reported \\
\hline & metformin-pioglitazone & Degludec & $\mathrm{I} .4 \%(\mathrm{D})$ & $2.6 \%(D)$ & \\
\hline & & Liraglutide & $1.3 \%(\mathrm{~L})$ & $0.2 \%(\mathrm{~L})$ & \\
\hline \multirow[t]{2}{*}{ NN9068-3697 (DUAL-II) ${ }^{54}$} & Type 2 diabetes patients & Degludec-Liraglutide & $0.74 \%$ & $0.30 \%$ & $0.10 \%$ \\
\hline & inadequately controlled on glargine & $\begin{array}{l}\text { Glargine to } \\
\text { maximum dose }\end{array}$ & $0.45 \%$ & $0.61 \%$ & $0.31 \%$ \\
\hline
\end{tabular}

Notes: For each of these major studies, the study population is listed along with the comparison agents, the percent reduction in $\mathrm{HbA}_{\mathrm{Ic}}$ for each group, and the number of overall hypoglycemic events and nocturnal hypoglycemic events. $* P<0.05$.

Abbreviations: $\mathrm{HbA}_{\mathrm{Ic}}$, glycated hemoglobin; PYE, patient-year of exposure. 
by $0.40 \%$ points (standard error 0.03 ) with degludec and $0.39 \%$ points with glargine ( $P$ : nonsignificant), and 188 $(40 \%)$ and 67 (43\%) participants achieved a target $\mathrm{HbA}_{1 \mathrm{c}}$ of less than $7 \%(<53 \mathrm{mmol} / \mathrm{mol})$. Rates of overall confirmed hypoglycemia were similar in the degludec and glargine groups (42.5 vs 40.2 episodes per PYE; estimated rate ratio [degludec to glargine] 1.07 [0.89-1.28]; $P=0.48$ ). The rate of nocturnal confirmed hypoglycemia was $25 \%$ lower with degludec than with glargine (4.41 vs 5.86 episodes per PYE; relative rate [RR]: 0.75 [0.59-0.96] 95\% CI; $P=0.021$ ).

The extended duration of degludec effect and low variability of insulin concentration has a large potential benefit; in the steady state, degludec can be given at any time of day. Novo Nordisk carried out proof of concept studies in the so-called FLEX trials where degludec was administered at variable times, spacing successive insulin shots for as long as 40 hours from one day to the next. ${ }^{35}$ A 26-week, open-label trial in type 1 diabetes patients compared degludec given in a fixed but flexible schedule daily with a minimum 8 and maximum 40 hours between doses (Forced-Flex) with degludec or glargine given strictly at the same time daily. In the 26-week extension, all degludec subjects were transferred to a regimen that allowed choosing variable any-time-of-day dosing (FreeFlex) and compared with subjects continued on glargine. After 26 treatment weeks, mean $\mathrm{HbA}_{1 \mathrm{c}}$ was reduced with degludec Forced-Flex $(-0.40 \%)$, degludec $(-0.41 \%)$, and glargine $(-0.58 \%)$. At week 52, degludec Free-Flex subjects had similar $\mathrm{HbA}_{1 \mathrm{c}}$ but greater FPG reductions than glargine subjects $(-1.07 \mathrm{mmol} / \mathrm{L})(P=0.005)$. Confirmed hypoglycemia rates (plasma glucose $<3.1 \mathrm{mmol} / \mathrm{L}$ or severe hypoglycemia) were similar at weeks 26 and 52. Nocturnal confirmed hypoglycemia occurred less frequently with degludec Forced-Flex vs degludec fixed dose $(37 \% ; P=0.003)$ and glargine $(40 \% ; P=0.001)$ at week 26 and $25 \%$ lower with degludec Free-Flex vs glargine $(P=0.026)$ at week 52 .

In a similar study, type 2 diabetes patients were randomized to, 1) once-daily degludec in a prespecified dosing schedule, creating 8-40-hour intervals between injections (degludec Flex; n=229); 2) once-daily degludec at the main evening meal (degludec; $n=228$ ); or 3 ) once-daily glargine at the same time each day $(\mathrm{n}=230) .{ }^{36}$ After 26 weeks, Flex dose degludec improved $\mathrm{HbA}_{1 \mathrm{c}}$ by $1.28 \%$ compared to $1.07 \%$ for degludec fixed time and $1.26 \%$ for glargine $(P$ : nonsignificant for the three treatments). There were no significant differences in hypoglycemia. ${ }^{36}$

A meta-analysis of hypoglycemia risk of degludec compared to glargine was performed over seven trials, five in type 2 diabetes and two in type 1 diabetes. There were
2,899 degludec patients and 1,431 glargine patients. In the overall type 2 population, significantly lower rates of overall confirmed episodes were reported with degludec as compared to glargine (RR: 0.83 [0.74; 0.94$] 95 \% \mathrm{CI}$ as well as nocturnal confirmed RR: 0.68 [0.57; 0.82] 95\% CI). In the type 1 population, the rate of nocturnal confirmed episodes was significantly lower with degludec than with glargine during maintenance treatment (RR: 0.75 [0.60; 0.94] 95\% CI). ${ }^{37}$

Studies also focused on the degludec-aspart 70/30 combination by comparing to detemir and separately administered premeal aspart. ${ }^{38}$ Adults $(n=548)$ with type 1 diabetes $\left(\mathrm{HbA}_{1 \mathrm{c}}: 7.0 \%-10.0 \%\right.$; body mass index $\left.\leq 35.0 \mathrm{~kg} / \mathrm{m}^{2}\right)$ were studied in a 26-week comparison of degludec-aspart given at a meal to detemir administered in the evening, with option of adding a breakfast dose. ${ }^{38} \mathrm{HbA}_{1 \mathrm{c}}$ improved by $0.75 \%$ with degludec-aspart and $0.70 \%$ with detemir and separate premeal aspart. There was no statistically significant difference between degludec-aspart and detemir in the rates of severe hypoglycemia ( 0.33 and 0.42 episodes/patient-year, respectively), but the rate of nocturnal confirmed hypoglycemia was 37\% lower with degludec-aspart (3.71 vs 5.72 episodes/patient-year, $P<0.05)$. Weight gain was $2.3 \mathrm{~kg}$ with degludec-aspart and $1.3 \mathrm{~kg}$ with detemir plus separate aspart doses $(P<0.05)$. Total insulin dose was $13 \%$ lower in the degludec-aspart group $(P<0.0001)$.

Novo Nordisk proposed that the long lasting, relatively invariable pharmacokinetics of degludec would be advantageous in clinical use. The concept is that, the longer the duration of a stable flat insulin concentration, the more possible it is to raise insulin levels to reduce fasting hyperglycemia without engendering hypoglycemia. The prolonged duration of action suggested that degludec could be administered three times weekly rather than daily. Novo Nordisk attempted to do this, but direct comparison trials between degludec given three times weekly and glargine given daily showed a greater tendency to hypoglycemia with degludec and worse glycemic control. ${ }^{39,40}$ In these studies, mean $\mathrm{HbA}_{1 \mathrm{c}}$ decreased by $0.9 \%$ on degludec given three times weekly in the morning compared to $1.3 \%$ for glargine and by $1.1 \%$ with degludec given three times weekly in the evening vs $1.4 \%$ for an evening dose of glargine, in both cases favoring glargine. Degludec administered three times weekly was associated with higher rates of hypoglycemia than daily administration, presumably due to requirement for a larger initial dose. Overall hypoglycemic events were similar for glargine and degludec given in the morning but higher for degludec given in the evening (rate ratio: 1.58, 1.03-2.43). Conversely, nocturnal hypoglycemic events occurred twice 
as frequently for degludec given three times weekly in the morning than for glargine (rate ratio: 2.12, 1.08-4.16). Given these unfavorable findings, Novo Nordisk decided to pursue degludec solely as a daily injection regime.

\section{Approval process for degludec}

Degludec and degludec-aspart were approved for marketing in Europe on January 22, 2013. The presentation of the pivotal efficacy and safety trials was interpreted as demonstrating superiority of degludec both to glargine and to detemir in treatment of type 1 and type 2 diabetes. Although there was no advantage in lowering of overall glucose levels as measured by $\mathrm{HbA}_{1 \mathrm{c}}$, degludec data suggested a reduction in hypoglycemic events.

In the US, it then came as a surprise at the US Food and Drug Administration (FDA) Advisory Committee Meeting when the team entrusted with the review of degludec data directly challenged the design and conclusions of the Novo Nordisk program. ${ }^{41}$ The issues raised by the FDA included the validity of claims of reduced risk of hypoglycemia with degludec, but, of even greater concern, what they considered a clear signal of questionable cardiovascular safety of this insulin.

The FDA statisticians carefully analyzed the hypoglycemia meta-analysis submitted by Novo Nordisk. Markedly different results in subpopulations of study subjects were noted. For example, degludec demonstrated significantly lower frequency of hypoglycemia than glargine, but only in type 2 diabetes patients with estimated rate ratio favoring degludec of 0.84 , with upper bound of the $95 \%$ CI equal to 0.93 . However, in the type 1 trials, the estimated ratio was 1.11 favoring glargine. Furthermore, the favorable rate ratio in type 2 diabetes did not occur in US subjects as compared to a $20 \%$ lower frequency of hypoglycemia in non-US patients. Moreover, the favorable rate ratio outside the US was primarily attributable to only one basal insulin trial (Trial 3579) with RR 0.69, compared to an RR of 1.27 in US patients. Dr Jean-Marc Guettier, the clinical reviewer, disputed the interpretability of hypoglycemia claims, calling into question the definition of confirmed hypoglycemia offered by Novo Nordisk, which included asymptomatic low glucose values. He noted that in the 3579 trial $^{32}$, there were more documented symptomatic hypoglycemic episodes caused by degludec than by glargine, although many more asymptomatic events were recorded by glargine participants. He also pointed out that the favorable hypoglycemia data offered by Novo Nordisk related to type 2 patients receiving only basal insulin. In these patients, hypoglycemia is much less frequent than in type 1 patients or in type 2 patients receiving mealtime rapidacting insulin. He also strongly challenged the claim of lower rates of nocturnal hypoglycemia with degludec, pointing out the difference in pharmacokinetics compared to glargine. Degludec injection is followed by a slow rise in insulin levels compared to glargine, which rapidly attains its peak value. Novo Nordisk defined nocturnal hypoglycemia as low glucose recorded between the hours of midnight and 6 AM. Dr Guettier suggested that the forced titration to achieve low fasting glucose values within this time period caused a design artifact favoring degludec. To illustrate his argument, he showed that, when expanded to the hours of midnight to $8 \mathrm{AM}$, there was no longer a difference favoring degludec.

However, it was not the disagreements regarding hypoglycemia that delayed the US approval of degludec. Rather, marketing approval was initially withheld due to concern regarding the results of the meta-analysis of cardiovascular events in the degludec program. In 2008, the clear evidence of cardiovascular harm resulting from use of the peroxisome proliferator-activated receptor agents led the FDA to issue new guidance for the evaluation of cardiovascular risk for diabetes drug development. ${ }^{42}$ In the past, approval of diabetes treatment agents was based primarily on effective glucose control. Safety was evaluated over a short period, typically 26-52 weeks, comparing active agents to placebo, followed by non-placebo-controlled "long-term" exposure, usually 2 years. As a result of embarrassments arising from postapproval events, such as the cardiovascular issues associated with the thiazolidinediones, the approach to assuring cardiovascular safety has changed in a continually evolving process. ${ }^{43}$ The FDA now requests that each submission contains a meta-analysis of all component Phase 2 and Phase 3 studies to determine a risk ratio for cardiovascular death for the agent considered for approval. It is suggested that the $95 \%$ upper bound of the risk ratio for the new agent compared to placebo be used as the criterion. An upper bound for the new agent of less than 1.3 would be considered reassuring. This new guidance has fundamentally changed the approach to approval of new agents for treatment of diabetes. In the case of degludec, the meta-analysis was not favorable.

The FDA analysis of cardiovascular safety of degludec focused on 16 trials of degludec and degludec-aspart, assessing major adverse cardovascular events (MACE). There was disagreement between Novo Nordisk and the FDA on the definition of MACE. Novo Nordisk wished to include unstable angina in addition to nonfatal myocardial infarction, nonfatal stroke, and cardiovascular death within the definition. The FDA felt that MACE should strictly exclude unstable angina. The hazard ratio calculated for the FDA definition in the degludec and degludec-aspart population was 1.67 , and, even with inclusion of unstable angina episodes, 
was still elevated at 1.3. Aspart insulin could be expected to raise the frequency of hypoglycemic episodes, triggering cardiovascular events. However, excluding degludec-aspart trials, with glargine as comparator to degludec, the database included 4,000 patients with the estimated hazard ratios similar to those in the overall degludec-aspart population. Based upon these findings, the FDA withheld initial approval for marketing in the US.

As a result of this disapproval, Novo Nordisk embarked on a long-term trial comparing degludec to other basal insulins in patients at increased risk of cardiovascular events. Early in the course of the trial, an interim analysis was quite reassuring, and in September of 2015, Dr Guettier concluded that the rate of events was comparable to that for other basal insulin products. This decision led to approval of marketing of degludec in the US. ${ }^{44}$

\section{Comparing degludec with glargine}

Insulin glargine has been the dominant form of basal insulin since its initial approval in 2000. The extended duration of action of glargine is due to decreased solubility at neutral subcutaneous tissue $\mathrm{pH}$, resulting in microprecipitation with subsequent slow release of insulin monomers. The Novo Nordisk basal insulin development program was more biochemically sophisticated, modifying the amino acid sequence of insulin to promote greater formation of hexamer dimers and self-association of these dimers. In addition, the attachment of a fatty acyl chain contributed to serum albumin binding further extending the duration of action. Detemir was the first basal insulin product marketed, but was not as long acting as glargine. Degludec, which has a much greater tendency to self-associate, has about twice as long a duration of action as glargine. This longer duration of activity is a potential advantage, although the hope to use a single injection over several days was not realized. Degludec administered three times weekly resulted in a higher rate of hypoglycemia with less reduction in $\mathrm{HbA}_{1 \mathrm{c}}$ than with glargine given daily. The release of degludec is more invariant in time than that of glargine insulin. This lower variability has been argued as more advantageous in preventing hypogycemic events. However, the definition of hypoglycemia proposed by Novo Nordisk, in particular nocturnal hypoglycemia, is somewhat biased by the pharmacokinetics of degludec in the overnight period. It is relevant to note that in the flexible dosing time studies, the purported advantage of degludec given at a fixed time as compared to glargine was not reproduced (Table 1).

Recently, the advent of U300 glargine has further mitigated the arguments favoring degludec insulin over glargine. This more concentrated glargine insulin preparation has a longer duration of insulin effect than the U100 preparation, and release of monomeric insulin also shows less variability. ${ }^{45-47}$

\section{Insulin combined with GLP- I agonists}

However, the single most important advantage that degludec possesses is not related to insulin activity at all. Rather, it is a new coformulation of degludec insulin with liraglutide, which suggests a new approach to the use of basal insulin, at least in type 2 diabetes. Liraglutide is a GLP-1 receptor agonist. GLP-1 is a 37 -amino acid peptide secreted from the L cells of the ileum and colon into the bloodstream. GLP-1 produces a glucose dependent increase in insulin secretion by the $\beta$ cell. Other significant effects of GLP-1 include suppression of glucagon secretion, slowing of gastric emptying time, and promotion of satiety. ${ }^{48}$ GLP-1 also stimulates differentiation and proliferation of $\beta$ cells and inhibits apoptosis. ${ }^{49}$ GLP-1 is rapidly degraded in the circulation by the enzyme dipeptidyl dipeptidase-4 (DPP-4). ${ }^{50}$ liraglutide is a GLP-1 analog modified to increase duration of action to allow a single daily dose. This agent was approved for treatment of diabetes in 2009. ${ }^{51}$ Very recently, liraglutide given at doses up to $3 \mathrm{mg}$ daily was approved for treatment for obesity as a separate indication. ${ }^{52}$ The benefits of GLP-1 analog treatment have been somewhat counterbalanced by the gastrointestinal disturbance that accompanies the altered bowel motility induced by GLP-1. ${ }^{53}$

The approach taken by Novo Nordisk was elegant and straightforward. Despite the complex polymeric character of degludec, it is possible to add liraglutide in a fixed ratio and maintain the pharmacokinetic properties of both agents unaffected by the other. Novo Nordisk formulated a fixed combination of 100 units $/ \mathrm{mL}$ degludec and $3.6 \mathrm{mg} / \mathrm{mL}$ liraglutide in the same dispensing pen. The pen dosage is given in "dose steps" consisting of 1 unit degludec and $0.036 \mathrm{mg}$ of liraglutide. The ability to modify and titrate the volume administered allows for true flexibility in dosage of liraglutide administered, so for 10 units of insulin, $0.36 \mathrm{mg}$ of liraglutide is coinjected. The upper limit of the currently marketed pen is 50 units of insulin and $1.8 \mathrm{mg}$ of liraglutide. This formulation of degludec insulin together with liraglutide provided an agent that combined the benefits of basal insulin treatment with those of GLP-1 while mitigating the disadvantages of each agent.

The approval studies were limited, given that numerous studies with degludec and with liraglutide administered individually have been completed and formed the basis of approval of the individual components. In a key 
proof-of-concept trial, type 2 diabetes patients inadequately controlled on metformin or metformin + pioglitazone were assigned to daily injections of degludec-liraglutide, degludec alone, or liraglutide alone $(1.8 \mathrm{mg} / \mathrm{d}) .{ }^{54}$ The initial dosages were 10 units for degludec alone, $0.6 \mathrm{mg}$ for liraglutide alone, and 10 dose steps for the degludec-liraglutide combination. The mean baseline $\mathrm{HbA}_{1 \mathrm{c}}$ was $8.3 \%$. The dose of degludec and of degludec-liraglutide was incremented twice weekly by 2 units or two dose steps, respectively, to achieve an eventual FPG target of 4.0-5.0 $\mathrm{mmol} / \mathrm{L}(72-90 \mathrm{mg} / \mathrm{dL})$. The dose of liraglutide was increased weekly by $0.6 \mathrm{mg}$ to a maximum of $1.8 \mathrm{mg}$. After 26 weeks, mean $\mathrm{HbA}_{1 \mathrm{c}}$ decreased by $1.4 \%$ to $6.9 \%$ with insulin alone, by $1.3 \%$ to $7.0 \%$ with liraglutide alone, and by $1.9 \%$ with the combination. The FPG levels were identical in the combined and insulin-only groups, although the dose of degludec reached in the degludec-liraglutide group was only 38 units compared to 53 units for degludec alone. The maximal dose of liraglutide attained was only $1.4 \mathrm{mg}$ in the combined group. As a result of the lower GLP-1 dose, fewer participants in the degludec-liraglutide group than in the liraglutide alone group reported gastrointestinal adverse events (nausea 8.8\% vs $19.7 \%$ ). As a result of the lower insulin levels, the number of confirmed hypoglycemic events per patient year was 1.8 for the combination, 0.2 for liraglutide alone, and 2.6 for insulin alone. After 26 weeks of treatment, mean body weight had decreased by $0.5 \mathrm{~kg}$ with degludec-liraglutide, increased by $1.6 \mathrm{~kg}$ with degludec alone, and decreased by $3.0 \mathrm{~kg}$ with liraglutide alone.

The combination of degludec and liraglutide was tested in patients with type 2 diabetes $\left(\mathrm{HbA}_{1 \mathrm{c}}: 7.5 \%-10.0 \%\right.$ on basal insulin [20-40 units]) and metformin with or without Sulfonylurea/Glinides. ${ }^{55}$ The maximal dose of degludec allowed in this trial was 50 units. Both groups reached a mean insulin equivalent of 45 units. $\mathrm{HbA}_{1 \mathrm{c}}$ decreased by $1.9 \%$ with the combination product and by only $0.9 \%$ $(10 \mathrm{mmol} / \mathrm{mol})$ with insulin alone. Mean weight reduction with degludec-liraglutide was $2.7 \mathrm{~kg}$ vs no weight change with degludec alone $(P<0.00010)$. The incidence of nausea was low in both groups $(6.5 \%$ for the combination vs $3.5 \%$ for insulin alone).

So, by combining liraglutide and degludec, patients achieve lower $\mathrm{HbA}_{1 \mathrm{c}}$, less hypoglycemia, less gastrointestinal symptoms, and relative weight loss. The clear superiority of combined degludec-liraglutide challenges the conventional approach to starting basal insulin alone in oral hypoglycemic treated patients. Sanofi (Paris, France) has made an effort to match the success of degludec-liraglutide by combining glargine with their GLP-1 agent lixisenatide.
Very recently, this combination has been approved for treatment of diabetes in the US. Unquestionably, Novo Nordisk has the advantage of having been first to market. In addition, their product benefits from the success of liraglutide in the LEADER Trial, which showed a $22 \%$ reduction in death from cardiovascular causes and a $15 \%$ decrease in overall mortality in liraglutide-treated, at risk, type 2 diabetes patients. ${ }^{56}$ In contrast, a trial of lixisenatide in patients who had suffered an acute coronary event demonstrated no mortality advantage. ${ }^{57}$ Although the trial designs were clearly different, the proven cardiovascular benefits of liraglutide certainly provide a substantial advantage for degludec in their coformulation.

\section{Conclusion}

Insulin degludec has been the product of a sophisticated and systematic biochemical engineering program that began with the release of insulin detemir. The goal was to produce a long-lasting basal insulin with low individual variability. Certainly, this goal has been achieved. Degludec has a duration of action approaching twice that of glargine. Another advantage of degludec is in its lack of unpredictable copolymerization of added aspart. Although the pharmacokinetic properties of aspart are affected by coadministration with degludec, the effect is sufficiently characterized to permit the use of a 70-30 mixture of the two insulins, with relatively stable serum insulin levels. This means that degludec-aspart, in this ratio, is useable much as NPH-aspart or NPH-Lispro mixtures. Novo Nordisk data suggested that degludec was even less likely than glargine to provoke hypoglycemia. In particular, nocturnal hypoglycemia was recorded as lower in both type 1 and type 2 patients. FDA reviewers did not agree with Novo Nordisk on their claim, suggesting that this finding may have been related to study design. They raised many objections, including the interesting observation that lower rates of hypoglycemia were only seen in non-US type 2 patients. They also questioned whether the rate of clinically serious hypoglycemia, as opposed to asymptomatic hypoglycemia, might not actually be higher for degludec than for glargine.

The most disquieting issue raised in the degludec approval process was the suggestion of a cardiovascular safety problem. Novo Nordisk proceeded with a long duration cardiovascular safety study in a large cohort, which assuaged the FDA concern that there might be an unfavorable cardiovascular effect unique to degludec. Nonetheless, the initial concerns fed into the long-term suspicions that elevated serum insulin may have an unfavorable effect on atherosclerosis. ${ }^{58}$ 


\section{Discussion}

The development of degludec was the result of a prolonged process of biochemical exploration of the self-association properties of insulin analogs. The goal for Novo Nordisk was to develop an agent that would aggregate in subcutaneous tissue with slow, constant release of insulin monomers. They first achieved this goal with detemir insulin, a useful product designed to compete with glargine. However, the duration of action of detemir was shorter than that of glargine, resulting in a primarily twice-a-day basal insulin. Further development led to degludec, with duration of action uncontestably longer than that of glargine. Degludec also carries the significant advantage of lower variability of insulin concentration than glargine. One can view the arrival of degludec insulin in the context of a continuous evolution of long-acting insulin products at Novo Nordisk, beginning with the work of Hagedorn on NPH insulin and continuing with Ultralente insulin, detemir and now degludec (Figure 1).
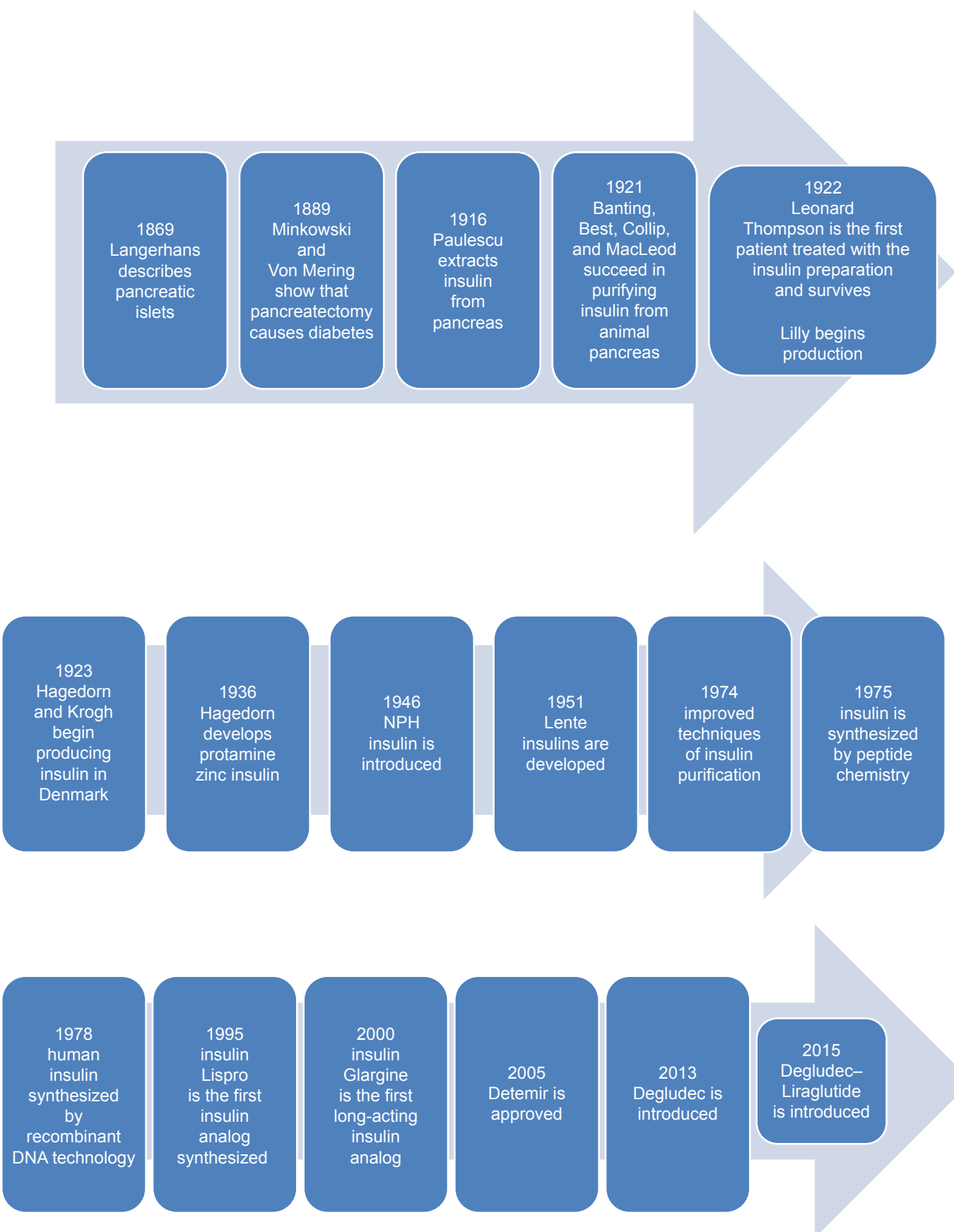

Figure I Timeline of development of insulin.

Note: Dates of major milestones in the history of insulin are shown.

Abbreviation: NPH, neutral protein hagedorn. 
Degludec provides a very stable release of insulin, suggesting that it is less likely to cause hypoglycemia due to peaks than glargine. However, in clinical use, there may not be a major advantage of degludec over glargine, particularly in light of the FDA analysis questioning the claim of a lower incidence of hypoglycemic events. Certainly, in several studies, including the flexible time administration studies, there was no difference in hypoglycemia frequency comparing degludec to glargine. Futhermore, the advent of U300 glargine blurs the purported differences since this more concentrated product appears to have a longer duration of action and lower variability than the U100 glargine formulation. The arguments over which basal insulin is superior may only be settled by long-term head to head trials. One such trial (DEVOTE) is now under way. ${ }^{59}$ DEVOTE was designed to evaluate the cardiovascular safety of degludec vs U100 glargine in patients with type 2 diabetes at high risk of cardiovascular events. The primary end point is the time from randomization to a composite outcome consisting of the first occurrence of cardiovascular death, nonfatal myocardial infarction, or nonfatal stroke. Patients at high risk of cardiovascular complications were randomized 1:1 to receive either degludec or glargine, each added to background therapies. DEVOTE enrolled 7,637 patients between October 2013 and November 2014 at 436 sites in 20 countries. Of these, 6,506 patients had prior cardiovascular disease or chronic kidney disease, and the remainder had multiple cardiovascular risk factors. This study should soon accumulate enough endpoint events to provide a definitive analysis of possible differences between glargine and degludec. Of course, there will not be an assessment of the more recently introduced U300 glargine formulation compared to degludec.

The argument over which basal insulin is superior may continue for a long time; yet this debate may be immaterial on a practical level. There are two major factors now intervening in the insulin market. The first is the introduction of multiple forms of biosimilar glargine insulin by several different manufacturers. These formulations may come at a lower cost than both degludec and U300 glargine. Given the drive by health authorities and payers to lower the cost of pharmaceuticals, the use of cheaper biosimilar glargine may be mandated. If so, the utilization of degludec may be very constrained.

The primary factor which could guarantee the future of degludec is the unquestionable advantage of the degludecliraglutide combination in type 2 diabetes patients. The decreased weight gain, improved glycemic control, and marked reduction in hypoglycemic events with this combination as compared to basal insulin alone are indisputable facts. Although the cost of two brand name drugs is certainly higher than for a biosimilar glargine, it is very difficult to deny these substantial advantages. So, it may become standard of care to start basal insulin combined with GLP-1 in type 2 diabetes. If so, the success of liraglutide will transfer to the degludec-liraglutide combination, perhaps assuring the future of use of degludec insulin as part of this combination product.

\section{Disclosure}

The author has been involved in several studies of degludec and also of U300 glargine. The author reports no other conflicts of interest in this work.

\section{References}

1. Rosenfeld L. Insulin: discovery and controversy. Clin Chem. 2002; 48(12):2270-2288.

2. Hagedorn HC, Jensen BN, Krarup NB, Wodstrup I. Protamine insulinate. JAMA. 1936;106(3):177-180.

3. Krayenbuhl C, Rosenberg T. Crystalline protamine insulin. Rep Steno Mem Hosp Nord Insulinlab. 1946;1:60-73.

4. Hallas-Moller K, Peterson K, Schlitchkrull J. Crystalline amorphous insulin-zinc compounds with prolonged action. Science. 1952;116: 394-396.

5. Hallas-Moller K, Jersild M, Petersen K, et al. The lente insulins, insulinzinc suspensions. Dan Med Bull. 1954;1:132-142.

6. Olsson PO, Hans A, Henning VS. Miscibility of human semisynthetic regular and lente insulin and human biosynthetic regular and NPH insulin. Diabetes Care. 1987;10(4):473-477.

7. Howey DC, Bowsher RR, Brunelle RL, et al. [Lys(B28), Pro(B29)]human insulin: effect of injection time on postprandial glycemia. Clin Pharmacol Ther. 1995;58(4):459-469.

8. Bolli GB, Owens DR. Insulin glargine. Lancet. 2000;356(9228): 443-445.

9. Owens DR, Coates PA, Luzio SD, et al. Pharmacokinetics of 125Ilabeled insulin glargine (HOE 901) in healthy men: comparison with NPH insulin and the influence of different subcutaneous injection sites. Diabetes Care. 2000;23(6):813-819.

10. Lepore M, Pampanelli S, Fanelli C, et al. Pharmacokinetics and pharmacodynamics of subcutaneous injection of long-acting human insulin analog glargine, NPH insulin, and ultralente human insulin and continuous subcutaneous infusion of insulin lispro. Diabetes. 2000;49(12):2142-2148.

11. Scholtz HE, Pretorius SG, Wessels DH, Becker RH. Pharmacokinetic and glucodynamic variability: assessment of insulin glargine, NPH insulin and insulin ultralente in healthy volunteers using a euglycaemic clamp technique. Diabetologia. 2005;48(10):1988-1995.

12. Fulcher GR, Gilbert RE, Yue DK. Glargine is superior to neutral protamine Hagedorn for improving glycated haemoglobin and fasting blood glucose levels during intensive insulin therapy. Intern Med J. 2005;35:536-542.

13. Herwig J, Scholl-Schilling G, Bohles H. Glycaemic control and hypoglycaemia in children, adolescents and young adults with unstable type 1 diabetes mellitus treated with insulin glargine or intermediate-acting insulin. J Pediatr Endocrinol Metab. 2007;20:517-525.

14. Rossetti P, Pampanelli S, Fanelli C, et al. Intensive replacement of basal insulin in patients with type 1 diabetes given rapid-acting insulin analog at mealtime: a 3-month comparison between administration of NPH insulin four times daily and glargine insulin at dinner or bedtime. Diabetes Care. 2003;26:1490-1496. 
15. Rosenstock J, Schwartz SL, Clark CM Jr, Park GD, Donley DW, Edwards MB. Basal insulin therapy in type 2 diabetes: 28 -week comparison of insulin glargine (HOE 901) and NPH insulin. Diabetes Care. 2001;24:631-636.

16. Rosenstock J, Dailey G, Massi-Benedetti M, Fritsche A, Lin Z, Salzman A. Reduced hypoglycemia risk with insulin glargine: a metaanalysis comparing insulin glargine with human NPH insulin in type 2 diabetes. Diabetes Care. 2005;28:950-955.

17. Havelund S, Plum A, Ribel U, et al. The mechanism of protraction of insulin detemir, a long-acting, acylated analog of human insulin. Pharm Res. 2004;21:1498-1504.

18. Plank J, Bodenlenz M, Sinner F, et al. A double-blind, randomized, dose-response study investigating the pharmacodynamic and pharmacokinetic properties of the long-acting insulin analog detemir. Diabetes Care. 2005;28:1107-1112.

19. Porcellati F, Rossetti P, Busciantella NR, et al. Comparison of pharmacokinetics and dynamics of the long-acting insulin analogs glargine and detemir at steady state in type 1 diabetes: a double-blind, randomized, crossover study. Diabetes Care. 2007;30:2447-2452.

20. Kolendorf K, Ross GP, Pavlic-Renar I, et al. Insulin detemir lowers the risk of hypoglycaemia and provides more consistent plasma glucose levels compared with NPH insulin in Type 1 diabetes. Diabet Med. 2006;23:729-735.

21. Hompesch M, Troupin B, Heise T, et al. Time-action profile of insulin detemir and NPH insulin in patients with type 2 diabetes from different ethnic groups. Diabetes Obes Metab. 2006;8:568-573.

22. Jonassen I, Havelund S, Hoeg-Jensen T, Steensgaard DB, Wahlund PO, Ribel U. Design of the novel protraction mechanism of insulin degludec, an ultra-long-acting basal insulin. Pharm Res. 2012;29 2104-2114.

23. Steensgaard DB, Schluckebier G, Strauss HM, et al. Ligand-controlled assembly of hexamers, dihexamers, and linear multihexamer structures by the engineered acylated insulin degludec. Biochemistry. 2013;52:295-309.

24. Haahr H, Heise T. A review of the pharmacological properties of insulin degludec and their clinical relevance. Clin Pharmacokinet. 2014;53: 787-800.

25. Hompesch M, Morrow L, Watkins E, Roepstorff C, Thomsen HF, Haahr H. Pharmacokinetic and pharmacodynamic responses of insulin degludec in African American, white, and Hispanic/Latino patients with type 2 diabetes mellitus. Clin Ther. 2014;36:507-515.

26. Heise T, Hövelmann U, Nosek L, Roepstorff C, Thomsen HF, Haahr H. Comparison of the pharmacokinetic and pharmacodynamic profiles of insulin degludec and insulin glargine. Expert Opin Drug Metab Toxicol. 2015;11:1193-1201.

27. Heise T, Nosek L, Bøttcher SG, Hastrup H, Haahr H. Ultra-long-acting insulin degludec has a flat and stable glucose-lowering effect in type 2 diabetes. Diabetes Obes Metab. 2012;14:944-950.

28. Heise T, Hermanski L, Nosek L, Feldman A, Rasmussen S, Haahr H. Insulin degludec: four times lower pharmacodynamic variability than insulin glargine under steady-state conditions in type 1 diabetes. Diabetes Obes Metab. 2012;14:859-864.

29. Havelund S, Ribel U, Hubálek F, Hoeg-Jensen T, Wahlund PO, Jonassen I. Investigation of the physico-chemical properties that enable co-formulation of basal insulin degludec with fast-acting insulin aspart. Pharm Res. 2015;32:2250-2258.

30. Kalra S. Insulin degludec aspart: the first co-formulation of insulin analogues. Diabetes Ther. 2014;5:65-72.

31. Biester T, Danne T, Bläsig S, et al. Pharmacokinetic and prandial pharmacodynamic properties of insulin degludec/insulin aspart in children, adolescents, and adults with type 1 diabetes. Pediatr Diabetes. 2016;17(8):642-649.

32. Zinman B, Philis-Tsimikas A, Cariou B, et al. NN1250-3579 (BEGIN Once Long) Trial Investigators. Insulin degludec versus insulin glargine in insulin-naive patients with type 2 diabetes: a 1-year, randomized, treat-to-target trial (BEGIN Once Long). Diabetes Care. 2012;35:2464-2471.
33. Garber AJ, King AB, Del Prato S, et al; NN1250-3582 (BEGIN BB T2D) Trial Investigators. Insulin degludec, an ultra-longacting basal insulin, versus insulin glargine in basal-bolus treatment with mealtime insulin aspart in type 2 diabetes (BEGIN Basal-Bolus Type 2): a phase 3, randomised, open-label, treat-to-target non-inferiority trial. Lancet. 2012;379(9825):1498-1507.

34. Heller S, Buse J, Fisher M, et al; BEGIN Basal-Bolus Type 1 Trial Investigators. Insulin degludec, an ultra-longacting basal insulin, versus insulin glargine in basal-bolus treatment with mealtime insulin aspart in type 1 diabetes (BEGIN Basal-Bolus Type 1): a phase 3, randomised, open-label, treat-to-target non-inferiority trial. Lancet. 2012;379(9825):1489-1497.

35. Mathieu C, Hollander P, Miranda-Palma B, et al; NN1250-3770 (BEGIN: Flex T1) Trial Investigators. Efficacy and safety of insulin Degludec in a flexible dosing regimen vs insulin glargine in patients with Type 1 Diabetes (BEGIN: Flex T1): a 26-week randomized, treat-to-target trial with a 26-week extension. J Clin Endocrinol Metab. 2013;98:1154-1162.

36. Meneghini L, Atkin SL, Gough SC, et al; NN1250-3668 (BEGIN FLEX) Trial Investigators. The efficacy and safety of insulin Degludec given in variable once-daily dosing intervals compared with insulin glargine and insulin Degludec dosed at the same time daily: a 26-week, randomized, open-label, parallel-group, treat-to-target trial in individuals with type 2 diabetes. Diabetes Care. 2013;36:858-864.

37. Ratner RE, Gough SC, Mathieu C, et al. Hypoglycaemia risk with insulin degludec compared with insulin glargine in type 2 and type 1 diabetes: a pre-planned meta-analysis of phase 3 trials. Diabetes Obes Metab. 2013;15:175-184.

38. Hirsch IB, Bode B, Courreges JP, et al. Insulin degludec/insulin aspart administered once daily at any meal, with insulin aspart at other meals versus a standard basal-bolus regimen in patients with type 1 diabetes: a 26-week, phase 3, randomized, open-label, treat-to-target trial. Diabetes Care. 2012;35:2174-2181.

39. Zinman B, Fulcher G, Rao PV, et al. Insulin degludec, an ultra-longacting basal insulin, once a day or three times a week versus insulin glargine once a day in patients with type 2 diabetes: a 16-week, randomised, open-label, phase 2 trial. Lancet. 2011;377(9769):924-931.

40. Zinman B, DeVries JH, Bode B, et al; NN1250-3724 (BEGIN:EASY AM) and NN1250-3718 (BEGIN:EASY PM) Trial Investigators. Efficacy and safety of insulin degludec three times a week versus insulin glargine once a day in insulin-naive patients with type 2 diabetes: results of two phase 3, 26 week, randomised, open-label, treat-to-target, noninferiority trials. Lancet Diabetes Endocrinol. 2013;1:123-131.

41. FDA Briefing Document: NDA 203313 and NDA 203314. Insulin Degludec and Insulin Degludec/Aspart. Applicant: Novo Nordisk, Inc. Endocrinologic and Metabolic Drugs. Advisory Committee Meeting. November 8, 2012.

42. U.S. Department of Health and Human Services Food and Drug Administration Center for Drug Evaluation and Research (CDER) Clinical Medical Guidance for Industry. Diabetes Mellitus - Evaluating Cardiovascular Risk in NewAntidiabetic Therapies to Treat Type 2 Diabetes. Silver Spring, MD: Office of Communications, Division of Drug Information, Center for Drug Evaluation and Research, Food and Drug Administration; 2008. Available from: http://wwwfda. govlcderlguidancelindex.htm. Accessed March 5, 2017.

43. Rendell M. The path to approval of new drugs for diabetes. Expert Opin Drug Saf. 2013;12:195-207.

44. Tresiba (degludec) and Ryzodeg. Bagsværd, Denmark: Novo Nordisk, Inc.Application No.: 203313Orig1 and 203314Orig1 Approval Date: September 25, 2015. Available from: www.accessdata.fda.gov/drug satfda.../203313Orig1s000_2033140rig1s000SumR.pdf. Accessed December 2, 2016.

45. Monnier L, Owens DR, Bolli GB. The new long-acting insulin glargine U300 achieves an early steady state with low risk of accumulation. Diabetes Metab. 2016;42:77-79.

46. Sutton G, Minguet J, Ferrero C, et al. U300, a novel long-acting insulin formulation. Expert Opin Biol Ther. 2014;14:1849-1860. 
47. Steinstraesser A, Schmidt R, Bergmann K, et al. Investigational new insulin glargine $300 \mathrm{U} / \mathrm{ml}$ has the same metabolism as insulin glargine 100 U/mL. Diabetes Obes Metab. 2014;16(9):873-876.

48. Drucker DJ. The biology of incretin hormones. Cell Metab. 2006;3: 153-165.

49. Gautier JF, Fetita S, Sobngwi E, Salaün-Martin C. Biological actions of the incretins GIP and GLP-1 and therapeutic perspectives in patients with type 2 diabetes. Diabetes Metab. 2005;31(3 Pt 1):233-242.

50. Drucker DJ, Nauck MA. The incretin system: glucagon-like peptide-1 receptor agonists and dipeptidyl peptidase- 4 inhibitors in type 2 diabetes. Lancet. 2006;368(9548):1696-1705.

51. Neumiller JJ, Campbell RK. Liraglutide: a once-daily incretin mimetic for the treatment of type 2 diabetes mellitus. Ann Pharmacother. 2009;43(9):1433-1444.

52. Astrup A, Carraro R, Finer N, et al; NN8022-1807 Investigators. Safety, tolerability and sustained weight loss over 2 years with the once-daily human GLP-1 analog, Liraglutide. Int J Obes (Lond). 2012;36(6): 843-854.

53. Tella SH, Rendell MS. Glucagon-like polypeptide agonists in type 2 diabetes mellitus: efficacy and tolerability, a balance. Ther $A d v$ Endocrinol Metab. 2015;6(3):109-134.

54. Gough SC, Bode B, Woo V, et al; NN9068-3697 (DUAL-I) trial investigators. Efficacy and safety of a fixed-ratio combination of insulin degludecand liraglutide (IDegLira) compared with its components given alone: results of a phase 3, open-label, randomised, 26-week, treat-to-target trial in insulin-naive patients with type 2 diabetes. Lancet Diabetes Endocrinol. 2014;2(11):885-893.
55. Buse JB, Vilsbøll T, Thurman J, et al; NN9068-3912 (DUAL-II) Trial Investigators. Contribution of liraglutide in the fixed-ratio combination of insulin degludec and liraglutide (IDegLira). Diabetes Care. 2014;37(11):2926-2933.

56. Marso SP, Daniels GH, Brown-Frandsen K, et al; LEADER Steering Committee; LEADER Trial Investigators. Liraglutide and Cardiovascular Outcomes in Type 2 Diabetes. N Engl J Med. 2016;28(375): 311-322.

57. Bentley-Lewis R, Aguilar D, Riddle MC, et al; ELIXA Investigators. Rationale, design, and Evaluation of LIXisenatide in Acute Coronary Syndrome, a long-term cardiovascular end point trial of lixisenatide versus placebo. Am Heart J. 2015;169(5):631-638.

58. Muis MJ, Bots ML, Grobbee DE, Stolk RP. Insulin treatment and cardiovascular disease; friend or foe? A point of view. Diabet Med. 2005; 22(2):118-126.

59. Marso SP, McGuire DK, Zinman B, et al. Design of DEVOTE (Trial comparing cardiovascular safety of insulin degludec vs insulin glargine in patients with type 2 diabetes at high risk of cardiovascular events) - DEVOTE 1. Am Heart J. 2016;179:175-183.
Drug Design, Development and Therapy

\section{Publish your work in this journal}

Drug Design, Development and Therapy is an international, peerreviewed open-access journal that spans the spectrum of drug design and development through to clinical applications. Clinical outcomes, patient safety, and programs for the development and effective, safe, and sustained use of medicines are the features of the journal, which

\section{Dovepress}

has also been accepted for indexing on PubMed Central. The manuscript management system is completely online and includes a very quick and fair peer-review system, which is all easy to use. Visit http://www.dovepress.com/testimonials.php to read real quotes from published authors. 